\title{
Identification of Two Novel $B C K D H B$ Mutations in Korean Siblings with Maple Syrup Urine Disease Showing Mild Clinical Presentation
}

\author{
Jung Min Ko ${ }^{1,2}$, Choong Ho Shin', Sei Won Yang ${ }^{1}$, Hae Il Cheong ${ }^{1-3, *}$, and Junghan Song ${ }^{4}$ \\ ${ }^{1}$ Department of Pediatrics, Seoul National University Children's Hospital, Seoul, Korea \\ ${ }^{2}$ Research Coordination Center for Rare Diseases, Seoul National University Hospital, Seoul, Korea \\ ${ }^{3}$ Kidney Research Institute, Medical Research Center, ${ }^{4}$ Department of Laboratory Medicine, Seoul National University College of Medicine, Seoul, Korea
}

\begin{abstract}
Maple syrup urine disease (MSUD) is a disorder that involves the metabolism of branched chain amino acids, arising from a defect in branched-chain $\alpha$-keto acid dehydrogenase complex. Mutations have been identified in the BCKDHA, BCKDHB, or $D B T$ genes, which encode different subunits of the BCKDH complex. Although encephalopathy and progressive neurodegeneration are its major manifestations, the severity of the disease may range from the severe classic type to milder intermediate variants. We report two Korean siblings with the milder intermediate MSUD who were diagnosed with MSUD by a combination of newborn screening tests using tandem mass spectrometry and family genetic screening for MSUD. At diagnosis, the patients' plasma levels were elevated for leucine, isoleucine, valine, and alloisoleucine, and branched-chain $\alpha$-keto acids and branched-chain $\alpha$-hydroxy acids were detected in their urine. $B C K D H A, B C K D H B$, and $D B T$ analysis was performed, and two novel mutations were identified in $B C K D H B$. Our patients were thought to have the milder intermediate variant of MSUD, rather than the classic form. Although MSUD is a typical metabolic disease with poor prognosis, better outcomes can be expected if early diagnosis and prompt management are provided, particularly for milder forms of the disease.
\end{abstract}

Key words: Maple syrup urine disease, $B C K D H B$, Novel mutation, Korean.

\section{Introduction}

Maple syrup urine disease (MSUD; OMIM\#248600) is a rare autosomal recessive aminoacidopathy caused by a defect in the branched-chain $\alpha$-keto acid dehydrogenase complex (BCKDH), a multi-subunit enzyme found in mitochondria that is involved in the metabolism of the branched chain amino acids (BCAAs) leucine, isoleucine, and valine. Impaired activity of the BCKDH complex causes accumulation of these three amino acids and their keto acid derivatives, leading to metabolic encephalopathy and progressive neurodegeneration in untreated patients [1]. It has an estimated prevalence of 1 in 185,000 worldwide $[1,2]$ and of 1 in 230,000 in Korea [3].

Disease-causing mutations have been identified in the $B C K D H A$, $B C K D H B$, and $D B T$ genes, which encode the $\mathrm{E} 1 \alpha, \mathrm{E} 1 \beta$, and $\mathrm{E} 2$ subunits of the BCKDH complex, respectively [2]. MSUD presents with varying clinical features, and its genotype is heterogeneous. MSUD can be classified into four clinical subtypes - classic, intermediate, intermittent, and thiamine-responsive - with de-

Received: 24 April 2014, Revised: 2 June 2014, Accepted: 3 June 2014, Published: 30 June 2014

*Corresponding author: Hae II Cheong, M.D., Ph.D.

Department of Pediatrics, Pediatric Clinical Neuroscience Center, Seoul National University Children's Hospital, 101 Daehak-ro, Jongno-gu, Seoul 110769 , Korea.

Tel: +82-2-2072-3570, Fax: +82-2-743-3455, E-mail: cheonghi@snu.ac.kr

Conflict of interest: We declare that we do not have any conflicts of interests.

(c) This is an open-access article distributed under the terms of the Creative Commons Attribution Non-Commercial License (http://creativecommons.org/licenses/by-nc/3.0/) which permits unrestricted non-commercial use, distribution, and reproduction in any medium, provided the original work is properly cited.

(c) Copyright 2014 by the Korean Society of Medical Genetics

www.e-kjgm.org 
creasing disease severity in this order. Among these, the classic form represents 75-80\% of all MSUD patients [1,4].

Early diagnosis and BCAA-restricted dietary treatment promote normal intellectual development and prevent neurological complications $[5,6]$. Therefore, in 2006, MSUD was added to the nationwide newborn screening (NBS) program for all newborns in Korea [3]. However, MSUD is quite rare, and less than 10 MSUD patients have been reported to date in Korea. Moreover, only 3 of these patients have received molecular confirmation of the diagnosis, and all of them had the classic form of the disease [7].

In this study, we present two siblings with MSUD arising from two novel $B C K D H B$ mutations who exhibited mild clinical courses and were thought to have a variant form of MSUD, which would be the first description of this disease type in Korea.

\section{Case}

\section{Patient 1 (younger brother)}

A 2-month-old Korean boy visited the Seoul National University Children's Hospital (Seoul, Korea) because of recurrent abnormal results of NBS for inherited metabolic diseases. He was born as a dizygotic twin with a birth weight of $2.80 \mathrm{~kg}$ at 37 weeks of gestation and was the third child born to healthy and nonconsanguineous parents. At the age of 3 days, an NBS performed using liquid chromatography/tandem mass spectrometry (LC-MS/MS) yielded an abnormal result. Therefore, a second-tier test was performed on day 20 after birth, and the result also revealed abnormally high levels of leucine $(550.5 \mu \mathrm{mol} / \mathrm{L})$ and valine $(382.8 \mu \mathrm{mol} / \mathrm{L})$. An amino acid analysis of the serum performed at the age of 34 days showed elevated concentrations of isoleucine $(299.9 \mu \mathrm{mol} / \mathrm{L})$, leucine $(749.9 \mu \mathrm{mol} / \mathrm{L})$, and valine $(605.1 \mu \mathrm{mol} / \mathrm{L})$. Alloisoleucine was also detected at the level of $58.2 \mu \mathrm{mol} / \mathrm{L}$. His urine organic acid analysis revealed elevated branched chain $\alpha$-keto acid and branched chain $\alpha$-hydroxy acid levels. MSUD was diagnosed biochemically, and a low-BCAA formula and thiamine supplementation were started on day 34 after birth.

At the age of 2 months, the initial examination in our hospital showed that the patient's height and weight were $59.6 \mathrm{~cm}$ (+0.75 standard deviation [SD]) and $5.1 \mathrm{~kg}(-1.0 \mathrm{SD})$. His head circumference was $39.4 \mathrm{~cm}$ (+0.73 SD). He did not show any pathological signs or symptoms for encephalopathy, and he could establish eye contact with his mother and exhibited social smiling. The follow-up serum amino acid analysis showed decreased levels of BCAA (isoleucine, $188 \mu \mathrm{mol} / \mathrm{L}$; leucine, $371 \mu \mathrm{mol} / \mathrm{L}$; and valine, $256 \mu \mathrm{mol} / \mathrm{L}$ ) and alloisoleucine (23 $\mu \mathrm{mol} / \mathrm{L}$ ) (Table 1). The plasma alloisoleucine- to-isoleucine ratio was 0.19 . The patient had normal levels of aspartate aminotransferase, alanine aminotransferase, glucose, and electrolytes. Ketone was not detected in the serum or urine. Brain and abdominal ultrasonography showed no abnormalities.

The patient is currently 9 months of age with a BCAA-restricted diet (isoleucine $40 \mathrm{mg} / \mathrm{kg}$, leucine $60 \mathrm{mg} / \mathrm{kg}$, and valine $45 \mathrm{mg} / \mathrm{kg}$, total protein $2.5-3.0 \mathrm{~g} / \mathrm{kg}$, and total calorie $120-130 \mathrm{kcal} / \mathrm{kg}$ per day) and thiamine supplementation, and shows a normal growth rate with regard to height $(74.0 \mathrm{~cm},+0.66 \mathrm{SD})$ and weight $(9.0 \mathrm{~kg}$, +0.0 SD), as well as normal developmental milestones, without any signs or symptoms of neurological deterioration. During the follow-up period, he had no acute episodes of metabolic derangement, and the levels of BCAAs had been normalized. Considering the clinical manifestations of the patient, he was thought to have the mild intermediate variant of MSUD, rather than the severe classic subtype.

\section{Patient 2 (elder brother)}

The elder brother of patient 1 was brought to the outpatient clinic of our institution at the age of 4.5 years for family screening of MSUD. Regarding his history, he was born with a birth weight of $3.65 \mathrm{~kg}$ at 40 weeks of gestation. An NBS that was performed using LC-MS/MS yielded normal results at that time. Although he showed

Table 1. Results of plasma amino acid analyses at diagnosis in two maple syrup urine disease siblings

\begin{tabular}{lcc}
\hline Amino acids & Patient 1 $(\mu \mathrm{M})$ & Patient 2 $(\mu \mathrm{M})$ \\
\hline Alanine & $301(143-439)$ & $150(120-600)$ \\
Arginine & $45(12-133)$ & $45(12-112)$ \\
Citrulline & $34(3-35)$ & $21(8-47)$ \\
Glutamic acid & $85(10-133)$ & $43(14-78)$ \\
Glutamine & $229(246-1,162)$ & $118(333-809)$ \\
Glycine & $183(81-436)$ & $135(107-343)$ \\
Alloisoleucine & $58.2(\mathrm{ND})$ & $59.0(\mathrm{ND})$ \\
Isoleucine & $299(31-86)$ & $159(6-122)$ \\
Leucine & $749(47-155)$ & $458(30-246)$ \\
Lysine & $159(66-270)$ & $49(66-270)$ \\
Ornithine & $151(22-103)$ & $34(20-136)$ \\
Phenylalanine & $64(22-108)$ & $38(26-98)$ \\
Proline & $167(52-298)$ & $150(40-332)$ \\
Serine & $77(71-186)$ & $101(70-194)$ \\
Threonine & $168(24-174)$ & $55(40-204)$ \\
Tyrosine & $64(22-108)$ & $33(19-119)$ \\
Valine & $605(64-294)$ & $482(132-480)$ \\
\hline
\end{tabular}

Values are presented as data (reference range).

Bold letters indicate abnormality.

Patient 1, younger brother; patient 2, elder brother. $\mathrm{ND}$, not detected. 
a mild delay in language development, his growth velocity with regard to height and weight and his motor development were normal. When he was 3.5 years of age, he was admitted to a regional hospital for 3 days because of severe dehydration and acute deterioration of his mental status associated with viral acute gastroenteritis. The levels of ketone in his urine were elevated, and intravenous rehydration with dextrose solution was required to recover his general and mental condition, although specific metabolic studies were not performed at that hospital.

At the age of 4.5 years, his height and weight were $104.5 \mathrm{~cm}(+0.16$ SD) and $16.0 \mathrm{~kg}(-0.42 \mathrm{SD})$, respectively. His head circumference was $51.0 \mathrm{~cm}(+0.20$ SD), and there were no abnormal findings upon physical examination. Serum amino acid analysis revealed ele-

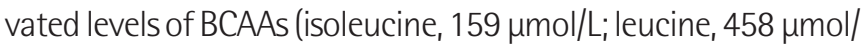
$\mathrm{L}$; and valine, $482 \mu \mathrm{mol} / \mathrm{L}$ ) and alloisoleucine ( $59 \mu \mathrm{mol} / \mathrm{L}$ ) (Table 1). His plasma alloisoleucine-to-isoleucine ratio was 0.37 . Branched chain $\alpha$-keto acids and branched chain $\alpha$-hydroxy acids were also detected in the urine. The levels of ketones and electrolytes in the serum were normal. MSUD was confirmed, and a BCAArestricted diet (isoleucine $400 \mathrm{mg} /$ day, leucine $600 \mathrm{mg} /$ day, and valine $450 \mathrm{mg} /$ day; total protein $35 \mathrm{~g} /$ day, total calorie 2,000 $\mathrm{kcal} /$ day) and thiamine supplementation were started. He was also thought to have the mild intermediate variant of MSUD.

\section{Molecular genetic analysis}

The parents of these patients provided formal informed consent to perform peripheral blood sampling for genetic analyses. All coding exons and exon-intron boundaries of the $B C K D H A, B C K D H B$, and $D B T$ genes were screened. No mutations were identified in the $B C K D H A$ and $D B T$ genes. The analysis of the $B C K D H B$ gene revealed the presence of two novel mutations in the siblings. They were heterozygous for two missense mutations: c.508C $>T$ (p.R170C) in exon 5 and c.673C>G (p.L225V) in exon 6 (Fig. 1). The mother and the father harbored the c.508C $>\mathrm{T}$ (p.R170C) and c.673C $>\mathrm{G}$ (p.L225V) mutations, respectively. Moreover, the remaining two siblings were carriers of one of the mutations identified here. All three in silico prediction algorithms predicted that the novel variants might affect protein function and might be pathological mutations (Table 2) [8-10].

\section{Discussion}

Traditionally, MSUD patients can be classified into different clinical phenotypes. The classic form, which is most severe with less than $2 \%$ of BCKDH activity, manifests itself within the neonatal period as poor feeding, seizures, and coma, and represents 75-80\%
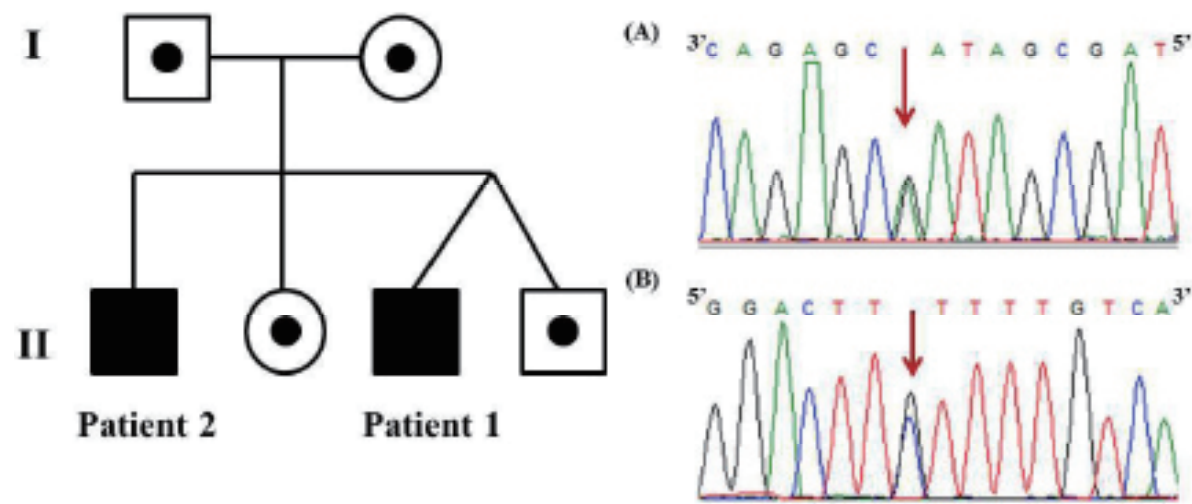

Fig. 1. The pedigree showed an autosomal-recessive inheritance pattern of the disease (left) Partial sequence of the $B C K D H B$ gene showing the mutations detected in patients 1 and 2 (right). (A) A heterozygous $\mathrm{C}>\mathrm{T}$ mutation at nucleotide 508 of exon 5 leads to the replacement of an arginine with a cysteine at codon 170 (c.508C >T, p.R170C). (B) A heterozygous C>G mutation at nucleotide 673 of exon 6 leads to the replacement of a leucine with a valine at codon 225 (c.673C $>$ G, p.L225V). The mother and the father harbor heterozygous c.508C >T (p.R170C) and c.673C > G (p.L225V) mutations, respectively.

Table 2. Two novel mutations identified in the $B C K D H B$ gene

\begin{tabular}{lccccc}
\hline Exon & Nucleotide change & Amino acid change & Mutation Taster prediction [9] & Polyphen prediction [8] & SIFT prediction [10] \\
\hline 5 & $\mathrm{C} .508 \mathrm{C}>\mathrm{T}$ & $\mathrm{R}^{2} 70 \mathrm{C}^{*}$ & Disease causing & Probably damaging & Affects protein function \\
6 & $\mathrm{C} .673 \mathrm{C}>\mathrm{G}$ & L225V* $^{*}$ & Disease causing & Probably damaging & Affects protein function \\
\hline
\end{tabular}

*These two residues are highly conserved across species such as Homo sapiens, Sus scofa, Bos taurus, Ailuropoda melanoleuca, Canis familiaris, Heterocephalus glaber, Rattus norvegicus, Mus musculus, Cavia porcellus, Gallus gallus, and Taeniopygia guttata.

SIFT, Sorting Intolerant from Tolerant program. 
of all patients. The remaining $20-25 \%$ of patients have milder variant forms, with later or episodic onset of symptoms and signs and $\mathrm{BCKDH}$ activity ranging from $2 \%$ to $40 \%$. There is a rare form that exhibits thiamine responsiveness where pharmacological doses of thiamine lead to normalization of the BCAA levels $[1,11]$.

MSUD is diagnosed based on the presence of typical clinical features and elevated levels of BCAA and alloisoleucine in the plasma and of branched-chain hydroxy acid and keto acid in the urine. In particular, a level of more than $5 \mu \mathrm{mol} / \mathrm{L}$ alloisoleucine in the plasma is a distinctive metabolic feature that is present in all forms of MSUD, whereas the plasma levels of BCAAs may be variable and are incomplete for the prognosis [12]. BCKDH enzyme activity, which can be measured using a variety of cell types, including skin fibroblasts, lymphocytes, or liver cells, is also important for diagnosis. However, previous studies have reported that enzyme activity measurements have variable accuracy and may not be clinically useful [13]. The plasma alloisoleucineto-leucine ratio can be used as an indirect indicator of disease severity because invasive procedures, such as skin biopsy, are not required for this test, and this ratio is inversely correlated with the BCKDH enzyme activity measured in fibroblasts [14]. The siblings described here showed ratios of 0.19 and 0.37 , respectively. These values are lower than those observed in patients with severe classic forms (0.59-0.72) and imply that our patients have milder variants [14].

Molecular genetic testing for the $B C K D H A, B C K D H B$, and $D B T$ genes has been used preferentially for diagnostic confirmation of MSUD. Differences in enzymatic activity and biochemical derangements among mutations in these 3 genes have not been found, and no strict genotype-phenotype correlations have been defined for MSUD $[15,16]$.

In this study, we identified two novel missense mutation variants in $B C K D H B$, p.R170C and p.L225V. This gene codes for the $E 1 \beta$ subunit that has transketolase activity. Although there is no known mutational hot spot, arginine 170 and leucine 225 are amino acids with a unique pattern in the pyrimidine-binding domain that are highly conserved across species. We were not able to perform a functional analysis to measure the residual enzyme activity in vitro. However, the novel variants identified in this study were thought to be pathological mutations that caused the loss of enzymatic activity because these variants were not found in $\mathbf{5 0}$ healthy Korean controls, and all three in silico algorithms used in this study predicted that the novel variants might affect protein structure and function (Table 1).

Since the benefit of NBS for MSUD was demonstrated for the first time in 1991 [17], early initiation of treatment after an early diagnosis via NBS has evidently resulted in fewer and less severe clinical symptoms and has yielded better neurodevelopmental outcomes [18]. The nationwide NBS program, including screening for MSUD, has been applied for all newborns in Korea since 2006. However, milder variant forms of MSUD, including the intermediate or intermittent type, can be missed during NBS. There are some reports of patients with variant forms that were not detected by NBS $[19,20]$, and our patient 2 is an example of such a missed case. Second-tier testing, including alloisoleucine and complementary application of the ratios of leucine to other amino acids, has been attempted and may improve NBS sensitivity for MSUD $[5,15]$

In summary, we report the identification of the first Korean family with the variant form of MSUD resulting from two novel $B C K D H B$ mutations. Although MSUD is a rare disease, and most of the patients with the classic form can be detected by NBS currently, milder variants of MSUD might escape NBS detection as was the case in patient 2. Thus, a high index of suspicion and repeated biochemical tests are necessary for the early detection and prevention of irreversible neurological complications, particularly in children showing delayed neurodevelopment with a history of unexplained ketonuria. Considering that MSUD is transmitted as an autosomal recessive condition and that interfamilial variability of the clinical manifestations is suggested, as observed in the siblings reported here, family screening using molecular genetic analysis should be performed in the patients' siblings, even if they show a normal result upon NBS.

\section{Acknowledgements}

We express our gratitude to the patients and their parents for their participation in this study. This study was supported by a grant of the Korean Health Technology R\&tD Project, Ministry of Health \& Welfare, Republic of Korea (HI12C0014).

\section{References}

1. Chuang DT, Shih VE. Maple syrup urine disease (branced-chain ketoaciduria). In: Scriver CR, Beaudet AL, Sly WS, Valle D, eds. The Metabolic and Molecular Basis of Inherited Disease. 8th ed. New York:McGraw Hill, 2001.

2. Nellis MM, Kasinski A, Carlson M, Allen $R$, Schaefer AM, Schwartz EM, et al. Relationship of causative genetic mutations in maple syrup urine disease with their clinical expression. Mol Genet Metab 2003;80:189-95.

3. Lee $\mathrm{DH}$. The prevalence of pediatric endocrine and metabolic diseases in 
Korea. Korean J Pediatr 2008:51:559-63.

4. Henneke M, Flaschker N, Helbling C, Müller M, Schadewaldt P, Gärtner J, et al. Identification of twelve novel mutations in patients with classic and variant forms of maple syrup urine disease. Hum Mutat 2003;22:417.

5. Strauss KA, Wardley B, Robinson D, Hendrickson C, Rider NL, Puffenberger EG, et al. Classical maple syrup urine disease and brain development: principles of management and formula design. Mol Genet Metab 2010;99:333-45.

6. Muelly ER, Moore GJ, Bunce SC, Mack J, Bigler DC, Morton DH, et al. Biochemical correlates of neuropsychiatric illness in maple syrup urine disease. J Clin Invest 2013;123:1809-20.

7. Park HD, Lee DH, Hong YH, Kang DH, Lee YK, Song J, et al. Three Korean patients with maple syrup urine disease: four novel mutations in the BCKDHA gene. Ann Clin Lab Sci 2011;41:167-73.

8. Adzhubei IA, Schmidt S, Peshkin L, Ramensky VE, Gerasimova A, Bork P, et al. A method and server for predicting damaging missense mutations. Nat Methods 2010;7:248-9.

9. Schwarz JM, Rödelsperger C, Schuelke M, Seelow D. MutationTaster evaluates disease-causing potential of sequence alterations. Nat Methods 2010;7:575-6.

10. $\mathrm{Ng} P \mathrm{PC}$, Henikoff S. Predicting deleterious amino acid substitutions. Genome Res 2001;11:863-74.

11. Simon E, Flaschker N, Schadewaldt P, Langenbeck U, Wendel U. Variant maple syrup urine disease (MSUD)--the entire spectrum. J Inherit Metab Dis 2006;29:716-24.

12. Schadewaldt $P$, Bodner-Leidecker $A$, Hammen HW, Wendel U. Significance of L-alloisoleucine in plasma for diagnosis of maple syrup urine disease. Clin Chem 1999;45:1734-40.

13. Schadewaldt $P$, Bodner-Leidecker $A$, Hammen HW, Wendel U. Wholebody L-leucine oxidation in patients with variant form of maple syrup urine disease. Pediatr Res 2001;49:627-35.

14. Wendel U, Langenbeck U, Seakins JW. Interrelation between the metabolism of L-isoleucine and L-allo-isoleucine in patients with maple syrup urine disease. Pediatr Res 1989;25:11-4.

15. Strauss KA, Morton DH. Branched-chain ketoacyl dehydrogenase deficiency: maple syrup disease. Curr Treat Options Neurol 2003;5:329-41.

16. Strauss KA, Puffenberger EG, Morton DH. Maple Syrup Urine Disease. In: Pagon RA, Adam MP, Ardinger HH, Bird TD, Dolan CR, Fong CT, et al., eds. GeneReviews [Internet]. Seattle (WA): University of Washington, 19932014. Available from http://www.ncbi.n/m.nih.gov/books/NBK1319/

17. Kaplan P, Mazur A, Field M, Berlin JA, Berry GT, Heidenreich R, et al. Intellectual outcome in children with maple syrup urine disease. J Pediatr 1991;119:46-50.

18. Simon E, Fingerhut R, Baumkötter J, Konstantopoulou V, Ratschmann R, Wendel $U$. Maple syrup urine disease: favourable effect of early diagnosis by newborn screening on the neonatal course of the disease. J Inherit Metab Dis 2006;29:532-7.

19. Puckett RL, Lorey F, Rinaldo P, Lipson MH, Matern D, Sowa ME, et al. Maple syrup urine disease: further evidence that newborn screening may fail to identify variant forms. Mol Genet Metab 2010;100:136-42.

20. Bhattacharya K, Khalili V, Wiley V, Carpenter K, Wilcken B. Newborn screening may fail to identify intermediate forms of maple syrup urine disease. J Inherit Metab Dis 2006;29:586. 